\title{
Using Motion Sensing for Learning: A Serious Nutrition Game
}

\author{
Mina C. Johnson-Glenberg and the EGL Lab group at Arizona State University \\ Learning Sciences Institute and Department of Psychology, University of Arizona, Tempe \\ Mina.Johnsoneasu . edu
}

\begin{abstract}
A mixed reality game was created to teach middle and high school students about nutrition and the USDA My Plate icon. This mixed reality game included both digital components (projected graphics on the floor) and tangible, physical components (motion tracking wands that were handheld). The game goal was to feed the alien the healthiest food item from a pair of items. Students learned about the amount of nutrients and optimizers in the digital food items and practiced making rapid food decisions. In the final level of the game players interacted with My Plate and each food item filled the appropriate quadrant in real time. Nineteen $4^{\text {th }}$ graders played through the game in one 1.5 hour session. Significant learning gains were seen on a pretest and posttest that assessed nutrition knowledge, paired $t_{(18)}=4.13, p<.001$. We support the need for call for more embodied games that challenge children to practice making quick food choice decisions and we explore how motion capture games can affect engagement, health behaviors, and knowledge outcomes.
\end{abstract}

Keywords: Applications: Education, Mixed Reality, Nutrition and Exer-Games.

\section{$1 \quad$ Introduction}

The rigorous design of health games and assessment of learning gains associated with such games is in its infancy. We present here a study that uses a mixed reality game platform and also explores metrics for assessing learning gains in such games. Mixed reality means a scenario has both digital components (projected graphics on the floor) as well as tangible, physical components (in this case students held a motion capture wand). To date, there has been little controlled, empirical support for the inclusion of games in formal education settings. A recent meta-analysis revealed some learning effects for exergames (Young, et al., 2012), but more research is required. Exergames are a natural extension of the new interfaces that have been popularized by the videogame entertainment industry (especially Wii FitTM and KinectTM platforms).

While there is increasing interest in exergames, current research shows mixed results for the use of systems to motivate behavior change. For example, although there are some data to suggest the possibility of promoting physical activity through systems like Wii Fit [Graves et al. 2010], a recent longitudinal three month study of the Wii Fit showed no significant health outcomes among its participants [Owens 
2011].) However, Souter (2008) observed a number of factors that motivated students to participate in the exergames. For example, students who were reluctant to participate in other physical activities or other social events were able to comfortably play the Wii with a group and be successful. That success then led to increased self-confidence, and some students were even motivated to try real sports after playing the Wii games. There is some evidence that games overcome a student's hesitancy and this overrides other factors like a child's gender or weight. Epstein, Beecher, Graf, and Roemmich (2007) studied overweight and nonoverweight children who exercised in a variety of different ways using dance dance revolution (DDR). The results showed that the children were more motivated to play $D D R$ with the interactive dance pad over the other non-dance options because of the interactive nature of the game and that the increased motivation did not depend on gender or weight status.

Video games for nutrition training. Less research has been done to attempt to integrate both healthful eating education and exergaming principles. To date, the closest research to explore this area has occurred within the realm of mobile health, particularly for weight loss. For example, SmartDiet (Lee, Chae, Kim, Ho, \& Choi, 2010) features a thin, normal weight, or overweight avatar, depending on the user's self-reported weight changes. While this study influenced fat mass, weight, and body mass index, the possibility for unintended consequences (e.g., increased prevalence of eating disorders) was not explored. The app was targeted toward overweight adults and uses self-reported diet and PA to calculate necessary caloric intake and expenditure for weight control. It also included a game that teaches users about nutrition and PA and features an avatar that reflects the user's weight change via the avatar's changing body shape (Lee et al., 2010).

Video games offer potential behavior change channels by embedding functional knowledge and change procedures such as goal setting, modeling, and skill development activities into a meaningful, entertaining, and immersive game environment (Baranowski, Buday, Thompson, \& Baranowski, 2008). One reason might be because these games create environments where players' actions and decisions can have immediate effects. This rapid feedback cycle coupled with the power of collaboration within games could be efficacious for altering students' decisions about food choices. Developing age-appropriate game-based intervention requires "substantial formative research (e.g., focus group discussions, intensive interviews, observations) with the targeted demographic group on story and character concept, story arc, personality and visual representation, and alpha testing on fun and functionality of the interactive components" (Baranowski, Buday, Thompson \& Baranowski, 2008. Further advice on game creation for this space comes from Rahmani and Boren (2012), who suggest that the interesting pieces of knowledge should be "hidden in the gameplay" and that story, graphics, and music be tightly designed and integrated in the play.

We are in the early stages of creating a nutrition game, but wanted to share the first study results because one of our goals is to create shared knowledge regarding the magnitudes of the effect sizes that researchers might expect from health game interventions. In addition, the field is in need of rapid-choice engaging, and valid nutrition assessments for the targeted age group. 


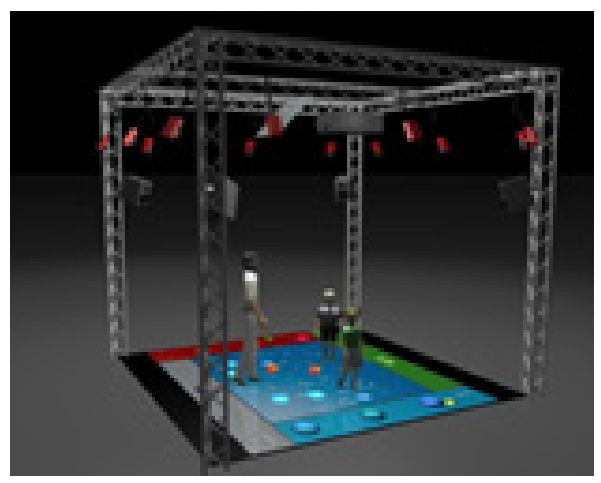

Fig. 1. Schematic of SMALLab

Learning in Mixed Reality Environments. The game in this study melded exercise with instruction on nutrition. There are several desktop games to teach children about nutrition, which are created on the model of one-child-to-one-screen. As such they are not embodied and they are not collaborative. The goal of our game was to engage an entire class in the instruction of nutrition while allowing two students to be active at a time. SMALLab (Situated Multimedia Arts Learning Lab) is a mixed reality educational platform that engages the major modalities (i.e., the sense systems including visual, auditory, and kinesthetic) that humans use to learn. SMALLab uses 12 infrared OPTITRACK motion tracking cameras either mounted in a ceiling (when in a classroom) or on a trussing system if in the research lab where this study took place. See Figure 1 for a schematic. The cameras send information to a computer about where a trackable object or "wand" is being held in the floor-projected environment. The space is called mixed reality because it meshes the digital virtual world with hands-on manipulables (Milgram \& Kishino, 1994). The floor space is 15 $X 15$ feet and the tracked space extends approximately eight feet high; wands are tracked with $\mathrm{X}, \mathrm{Y}, \mathrm{Z}$ coordinates up to one millimeter in precision. Using the wand (a rigid body trackable object with retro-reflective markers on the ends), the physical body can now function like a 3D cursor in the interactive space. For example, by dipping down with the wand a virtual object projected on the floor can be "grabbed" by the wand and moved to other locations for immediate scoring and feedback similar to a click and drag action on a computer screen. Some notable differences between this platform and a traditional desktop one are that students can locomote through the immersive environment and be active; further many peers can partake in observational learning and real time discourse.

SMALLab allows for multiple students (up to four) to be tracked simultaneously. With turn-taking, entire classrooms with 30 students are able to physically experience a learning scenario in a typical class period. Students outside the active space sit around the open periphery and collaborate by discussion and whiteboard activities. The lab at ASU has researched the efficacy of the mixed reality platform in several content domains including language arts (Hatton, Birchfield, \& Megowan, 2008), science, technology, engineering, and mathematics [STEM] - physics (JohnsonGlenberg, Birchfield, Savvides, \& Megowan-Romanowicz, 2011; Tolentino, 
Birchfield, Megowan-Romanowicz, Johnson-Glenberg, Kelliher \& Martinez, 2009) geology (Johnson-Glenberg, Birchfield, \& Usyal, S., 2009) and Disease Transmission (Johnson-Glenberg, Birchfield, Tolentino, \& Koziupa, in revision). This range suggests that embodied learning in mixed reality is not content dependent.Design principles in game. The lab follows several principles of design as it co-creates content with teachers and subject matter experts. Content always incorporates components of embodiment with gestural congruency and collaboration - we expand on these constructs in the following sections. The game begins with the narrative of the player (you) finding a lost and hungry alien under your bed. Coincidentally, the alien's body functions similarly to a human's and you must feed him and get him back to health so he can get home. The first student in the space takes the role of the selector and the other student is the transporter. Figure 2 shows an example of the floor projection. A forced choice task is shown in the top right corner. The selector hovers the motion tracking wand over a food item and on the top left of the space the nutrients present in that item begin to glow. We highlight three nutrients (protein, carbohydrates and fatty acids) and two 'optimizers' (fiber and vitamins/minerals; note these were chosen based on expert consultation from a registered dietician). The selector "picks" the virtual item up and with the wand brings it to the alien's mouth, where a chewing animation follows. At that point, feedback is shown regarding the quality of the choice. When the better choice is picked (in Figure 2 that would be the bowl of blueberries with less fat and more fiber), the alien stays green and smiling; had the piece of pie been chosen the alien would display the beginning of five stages of decline into sleep or lower alertness. In the final stage, the alien is a sallow yellow with drooping antennae, closed eyes and no smile.

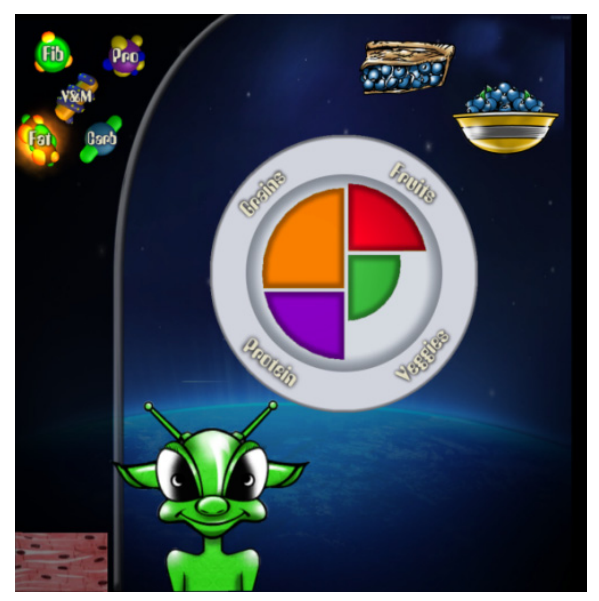

Fig. 2. Example of the floor projection 
Now, the transporter player needs to grab the glowing nutrients at the top of the play space and physically "run" them down to the tissue at the bottom of the space. All nutrients that are lit up must be transported before the next food pair can appear. Thus, the transporter is encouraged by his/her peers on the sidelines to hustle to get the nutrients down to the tissue area to continue the game. We specifically wanted to design in high levels of activity for at least one of the players.

The five "nutrients." We wanted children to have practice rapidly choosing food they might be exposed to in a day at home, stores, or school. Two subject matter experts (i.e., a registered dietician and a nutrition professor) were consulted extensively during the design of the game. We did not want to focus on simple calorie counts because children do not seem to make rapid decisions this way and because, overall, we were more interested in emphasizing food quality over caloric quantity. Our goal was to get children to think about foods that satiate, and were "more" nutritious in a comparative manner. They need practice making quick choices about what "to grab in a cafeteria line" or in a store during a busy day. The use of the alien avatar allowed for a human physique that would react immediately to the foods but not get "fat." We did not think this would be appropriate for classes that would surely contain a spectrum of body sizes and shapes. The decision was made to give feedback on nutritional value via drowsy sleep states.

We needed to keep the number of nutrients tractable, so no more than five are listed with four levels of magnitude: $0=$ outline, $1=\operatorname{dim}, 2=$ bright, $3=$ bright and spinning. We chose these nutrients as these represent broad nutritional domains important for understanding food quality. With regard to food quality metrics, a balance was sought between providing enough information to aid children in making better decisions, while not complicating matters too much, thereby reducing retention of the learning objectives.

\section{Methods}

Participants. Nineteen $4^{\text {th }}$ graders were recruited from a K-8 school in an urban city. The class was $80 \%$ Caucasian, 10\% African American and 10\% Hispanic. Though it was the end of the school year, they had not yet received a unit on health and nutrition.

Procedure. One week before students came to the University lab to play the videogame, two experimenters went to the school to administer the two pretests. The following week, the students arrived and played the game at the same time of day (before lunch). Immediately upon finishing their turn, the pair of students was taken into another room to complete the two invariant posttests (this took about 15 minutes). When the students finished the posttests, they were escorted back into the main play area of SMALLab to observe their peers in the game. Each pair was assigned an ordinal pair number so order of play effects could be tested. The hypothesis was that the more a student was able to observe the gameplay (i.e., the higher the pair number), the higher the gains would be by posttest. 
Gameplay. The first author led the gameplay session. Student pairs were quasirandomly chosen. Volunteers were sought and enthusiasm played a role as to the order they were called upon, as well as the desire to create mix gender pairs. Each pair played approximately eight minutes, in the middle of play, the pair switched roles of selector and transporter. Again, one student (the selector) selected the food with the wand, verbally checked with the transporter for agreement on choice, and then carried it to the alien's mouth. When the alien started to chew, the second student (the transporter) brought the now-active nutrients down to the tissue at the bottom of the playspace. The three nutrients were protein, carbohydrates and fatty acids, and the two 'optimizers' were fiber and vitamins/minerals. After the end of the first full play session, two of the practice levels were skipped since all students had seen those with earlier players. At a later level, we introduced the My Plate icon. The experimenter went over the names of the food groups and kept instruction brief, saying, "In general, you should try to eat more fruits and vegetables and fewer grains and proteins." The circle for dairy that some templates include was not used because the dairy requirement is considered by some to be controversial. When the selector chose a food item the appropriate section or quadrant of the My Plate icon would begin to fill. We mapped the item to one serving - or a portion that a 12 year-old male would eat for a lunch so the grilled fish was deemed one serving and it filled up one third of the protein section of the My Plate template. An apple would fill one fourth of the fruit section. (These portions will be refined in future iterations.) The figure above shows the icon filled except for the vegetables.

Nutrition and Food Choice Test - This experimenter-designed test was a mixture of forced choice and open-ended items. While we did find several potential measures to use related to nutrition knowledge (e.g., see Townsend, Johns, Shilts, \& FarfanRamirez, 2006; Wall, Least, Gromis \& Lohse, 2012), we could not find a measure that was in line with the educational content specifically focused upon within this test, particularly for this age group. This new measure was piloted with a focus group of 9 year-olds before the study. It includes 31 items and a blank My Plate template that students were asked to fill in. The maximum score on the test was 100 , this was never reached. The highest score at posttest was 95 .

\section{Results}

Students were assessed with pretests one week before play and then immediately after. The Descriptives and effect sizes (Cohen's $d$ ) are listed in Table 1.

Table 1. Descriptives for Alien Health-SMALLab

\begin{tabular}{|c|c|c|c|c|}
\hline$\underline{\text { Test }}$ & $\frac{\text { Pretest }}{M \text { and SD }}$ & $\underline{\text { Posttest }}$ & Difference & $\underline{\text { Effect Size }}$ \\
\hline Nutrition Test & & & & \\
\hline $\begin{array}{l}\text { Total Test } \\
\text { My Plate Sub }\end{array}$ & $70.87 \quad(11.32)$ & 77.95 (13.66) & 7.08 & .57 \\
\hline Items & (4.48) & $11.17(5.01)$ & 3.43 & .72 \\
\hline
\end{tabular}




\section{Discussion}

The results indicate that one 1.5 hour session in a mixed reality game environment can have positive impacts on knowledge about nutrition. Statistically significant gains were seen in explicit knowledge regarding food choices on a nutrition test. There is evidence of transfer of knowledge of general principles related to nutrition because over half of the items on the nutrition test were new items that students had not seen in the game. In addition, students learned about My Plate categories and proportions by playing the game, on this subtask they displayed a large effect size in learning of .72 by the end of play. This is interesting because students received only cursory instruction on My Plate, they were told it replaced the Food Pyramid icon. The experimenter went over the four food group labels only once and said, "In general, you should try to eat more fruits and vegetables and fewer grains and proteins." The icon for dairy was not used because it was deemed somewhat controversial by our expert nutritionist panel. This suggests that exposure to and short interactions with the icon during play may be instructive and result in significant knowledge change, though additional research is required to fully delineate the active mechanism of knowledge transfer.

Implications. We contend that instructional gameplay in a mixed reality environment holds great promise for nutrition education and whole class participation. Active whole class participation is difficult to achieve with more traditional multimedia designs when each child is viewing an individual screen. Students reported being "very interested in" and engaged with the alien storyline and showed strong evidence of transfer to new nutrition facts and to the My Plate icon. We are currently researching how to facilitate an entire class exercising with the active players in the game and are creating a vertical, on-the-wall version using the Microsoft Kinect ${ }^{\mathrm{TM}}$ as the input device. Our goal is to have the game used in a PE and/or nutrition classes.

Limitations. As this was a first-generation game study focused on determining the feasibility of a multimodal game to promote nutrition knowledge, there were several limitations. First, there was no control condition. The school we had access to had two fourth grade teachers, but the second teacher did not want to be part of the study since she "had no plans" to cover nutrition the entire school year. It did not seem prudent to have a "business as usual" control condition if the class would not focus on nutrition for 1.5 hours. Further, there were too few students in the experimental class to do a split class waitlist design, which we have done for other SMALLab studies. For the next iteration of studies we will bring the mobile KINECT camera to the classroom and recruit several schools.

Future Directions. The advent of cost effective skeletal tracking systems like the Xbox Kinect could have a positive effect on exercise in home and classroom setting. We are currently designing a game based on many of the lessons learned with this mixed reality game. We want to get all the passively viewing member of the class to participate even if they are not being tracked by the system. The nutrition or PE teacher could encourage those who are getting automated feedback to do projected 
exercises on the sideline. Xbox Kinect may prove to be a "game changer" in the exergames domain (Boulos, 2012).

Future iterations of the game should be more precise about proportion of food that a child should eat in a day, especially in reference to the My Plate quadrants. With the Kinect we are able to track the size of the child and make the plate portion fill accordingly. For example, a short child with a slim outline would require fewer servings of protein in a day, this information can be instantly translated into gameplay. We are currently researching the pros and cons of making the avatars take on the body morphology of the active student. (This may only be appropriate for at home play because of children's social discomfort.)

Conclusions. Games hold much promise for instructing young people in nutrition, in addition games can be key motivators in getting students active during the school day or in afterschool care. We present a mixed reality game that uses a large open space and allows the non-active students to also learn about nutrition and My Plate. Significant gains were seen on a nutrition test after 1.5 hours of play for an entire class. One goal is to give students practice making fast food decisions that may carry over into real life. We are working to revise an engaging food choice test using replica food items to better assess this type of transfer.

Acknowledgements. Special thanks to Eric Heckler, Maureen Zimmerman, Tatyana Koziupa, Caroline Savio-Ramos, Chris Dean, Ben Luke, Sean Griffin, Sarah Cargill and Punam Ohri-Vachaspathi.

\section{References}

1. Baranowski, T., Buday, R., Thompson, D.I., Baranowski, J.: Playing for Real: Video Games and Stories for Health-Related Behavior Change. American Journal of Preventitive Medicine 34(1), 74-82 (2008)

2. Barsalou, L.W.: Grounded Cognition. Annual Review of Psychology 59, 617-645 (2008)

3. Boulos, M.: Xbox 360 Kinect Exergames for Health Games. Research, Development, and Clinical Applications 1(5) (2012), doi:10.1089/g4h.2012.0041

4. Davis, C.L., Tomporowski, P.D., Boyle, C.A., Waller, J.L., Miller, P.H., Naglieri, J.A., Gregoski, M.: Effects of aerobic exercise on overweight children's cognitive functioning: a randomized controlled trial. Research Quarterly of Exercise and Sport 78(5), 510-519 (2007)

5. Dustman, R.E., Emmerson, R.Y., Steinhaus, L.A., Shearer, D.E., Dustman, T.J.: The effects of videogame playing on neuropsychological performance of elderly individuals. J Gerontol 47(3), 168-171 (1992)

6. Dustman, R.E., Ruhling, R.O., Russell, E.M., Shearer, D.E., Bonekat, H.W., Shigeoka, J.W., Bradford, D.C.: Aerobic exercise training and improved neuropsychological function of older individuals. Neurobiology of Aging 5(1), 35-42 (1984), http: / / dx.doi.org/10.1016/0197-4580

7. Epstein, L.H., Beecher, M.D., Graf, J.L., Roemmich, J.N.: Choice of interactive dance and bicycle games in overweight and nonoverweight youth. Ann. Behav. Med. 33(2), 124-131 (2007), doi:10.1080/08836610701307835 
8. Gee, J.: Good Video Games and Good Learning: Collected Essays on Video Games, Learning and Literacy (New Literacies and Digital Epistemologies). Peter Lang Pub. Inc. (2007)

9. Graves, L.E.F., Ridgers, N.D., Williams, K., et al.: The Physiological Cost and Enjoyment of Wii Fitin Adolescents, Young Adults, and Older Adults. Journal of Physical Activity and Health, 393-401 (2010)

10. Grunbaum, J.A., Kann, L., Kinchen, S.A., Williams, B., Ross, J.G., Lowry, R., Kolbe, L.: Journal of School Health 72(8), 313-328 (2002), doi:10.1111/j.1746-1561.2002.tb07917.x

11. Hatton, S., Birchfield, D., Megowan-Romanowicz, C.: Learning metaphor through mixedreality game design and game play. In: Paper presented at the Proceedings of the 2008 ACM SIGGRAPH Symposium on Video Games, Los Angeles, California (2008)

12. Jenkins, H., Clinton, K., Purushotma, R., Robison, A., Weigel, M.: Confronting the Challenges of Participatory Culture: Media Education for the 21st Century: MacArthur Foundation (2006)

13. Johnson-Glenberg, M.C., Birchfield, D., Savvides, P., Megowan-Romanowicz, C.: Semi-virtual Embodied Learning-Real World STEM Assessment. In: Annetta, L., Bronack, S. (eds.) Serious Educational Game Assessment, pp. 241-257. SensePublishers (2011)

14. Johnson-Glenberg, M.C., Birchfield, D., Usyal, S.: SMALLab: Virtual geology studies using embodied learning with motion, sound, and graphics. Educational Media International 46(4), 267-280 (2009)

15. Lee, W., Chae, Y.M., Kim, S., Ho, S.H., Choi, I.: Evaluation of a mobile phone-based diet game for weight control. J Telemed Telecare,16(5), 270-275 (2010), doi: jtt.2010.090913 [pii] 10.1258/jtt.2010.090913

16. Maillot, P., Perrot, A., Hartley, A.: Effects of interactive physical-activity video-game training on physical and cognitive function in older adults. Psychology and Aging 27(3), 589-600 (2012)

17. Milgram, P., Kishino, F.: A Taxonomy of Mixed Reality Visual Displays. IEICE Transactions on Information Systems, E77-D(12)(1994), doi: citeulike-article-id:477597

18. Owens, S.G., Garner, J.C., Loftin, J.M., van Blerk, N., Ermin, K.: Changes in Physical Activity and Fitness after 3 months of Home Wii Fit use. Journal of Strength \& Conditioning Research 25(11), 3191-3197 (2011)

19. Souter, J.: Nintendo Wii as an inclusive learning tool. Disability Support Services Unit Online Newsletter 7(3) (2008)

20. Thomas, H.: Obesity prevention programs for children and youth: why are their results so modest? Health Education Research 21(6), 783-795 (2006), doi:10.1093/her

21. Thompson, R., Jago, R., Griffith, M.J., Thompson, D., Baranowski, T., Buday, R., Baranowski, J.: Development of a Serious Video Game. Simulation Gaming 41, 587 (2010)

22. Tolentino, L., Birchfield, D., Megowan-Romanowicz, C., Johnson-Glenberg, M.C., Kelliher, A., Martinez, C.: Teaching and Learning in the Mixed-Reality Science Classroom. Journal of Science Education and Technology 18(6), 501-517 (2009), doi:10.1007/s10956-009-9166-2

23. Townsend, M., Johns, M., Shilts, M.K., Farfan-Ramirez, L.: Evaluation of a USDA nutrition education program for low-income youth. Journal of Nutrition Education and Behavior 38, 30-41 (2006)

24. USHHS. Physical Activity Guidelines for Americans (2009), http: / /www. govtrack. us/congress/bills/111/hr3851 
25. Wall, D.E., Least, C., Gromis, J., Lohse, B.: Nutrition education intervention improves vegetable-related attitude, self-efficacy, preference, and knowledge of Pennsylvania fourth grade students. Journal of School Health 82(1), 37-43 (2012)

26. Watts, K., Jones, T.W., Davis, E.A., Green, D.: Exercise Training in Obese Children and Adolescents: Current Concepts. Sports Medicine 35(5), 375-392 (2005)

27. Young, M.F., Slota, S., Cutter, A.B., Jalette, G., Mullin, G., Lai, B., Yukhymenko, M.: Our Princess Is in Another Castle: A Review of Trends in Serious Gaming for Education. Review of Educational Research 82(1), 61-89 (2012), doi: citeulike-article-id:10312339, $10.3102 / 0034654312436980$ 